

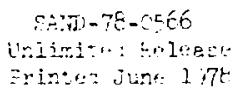

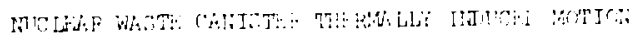

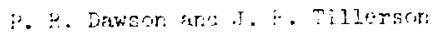

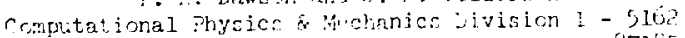

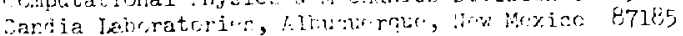

\section{A. DETFACT}

The movement of canisters containing heat producing nuclear wastes has been analyzed using a aingle canister model in a salt environnent. Steady state and transient analyses both indicate that only minimal carister movement will result from buoyency of heated salt.

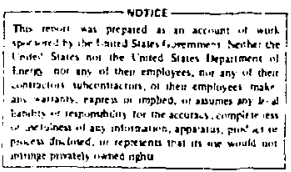




\section{TABLE OT CONTENTS}

Page

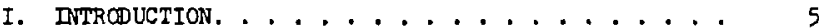

II. THERMOMECHANICAL SOLUTION METHODS . . . . . . 7

III. CANISTER AND SALT MODELING, ........... 12

IV. PREDICTIONS OF CANISTER AND SALT MOVEMENT . . . . 15

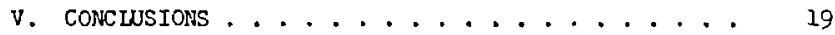




\section{RNTRODUCTION}

The movement of canisters containing heat generating nuclear wastes burled in a enit repository has been questioned. The existence of buoyant forces due to thermally produced denslty differences suggests the possibility of lnitlating convective cells in a plastic medium like salt. A proper assessment of this motion includes consideration of thr temperature dependence of the effective viscosity and thermal conductivity of the salt as well as decrease in the thermal output of the heat generating wastes with time.

A thermomechanically coupled formulation for creeping viscous flow and heat transfer that includes the features mentioned earlier has been used to predict canister motion. The large deformation creeping behavior of the salt over long periods of time was represented as a viscous fluid with temperature dependent viscosity. Deformations were required to be inconpressible and elastic response of the salt was assumed to be negligible in comparison to the viscous streins. The conductive-convective heat transfer equation was solved to obtain the temperature distributions within the salt-canister system. Temperature dependent tbermel condrctivity was included in the analyses. Coupling between the flow field and temperature distribution resulted from temperature dependent material properties, temperature dependent body forces, viscous dissipation and changes in the system geometry. The Boussinesq approximation was applied in these analyses so that only the body forces in the equilibrium equation were affected by changes in the salt density. Free expansion of the salt with tempereture rises was assumed for the purpose of computing these body forces. This assumption led to the largest density differences and 
therefore the greatest driving forces for upward salt flow. Separate thermelastic computations were performed to evaluate the validity of this free expansion essumption.

An axisymmetric region $500 \mathrm{~m}$ in radius that extended $750 \mathrm{~m}$ above and below the canister elevation was analyzed. Transient creeping flow and heat transfer anelyses began wjth an initial undeformed isothermal region and followed the movement of the canister as the salt heated and a convective cell formed. The heat scurce resulted from the radioactive decay of the wastes in the canister. The source diminishec with time based on $a$ thirty year half life (a realistic approximation for heat producing nuclear wastes). The temperature fields predicted in the transient analyses served as input to the thermoelestic studies. Steady-state creeping flow and heat transfer analyses were used to predict an upper bound on the magnitude of velocities. For the steady-state analyses, velocity fields and temperature distributions were computed assuming that the canister thermel output was constant (and equal to the maximum power for all times). Eecause the waste heat output decays with time, the actual temperatures would never reach values predicted using the constant source. Thus, velocities predicted usine the steady-state temperature field grossly overestimate actual velocities. 
Computer codes based on the finite element method were ut1lized to predict the creeping viscous and thermolestic expansion of the salt in the region of analysis. The creeping viscous flow computations were performed using the COUPLEFLO $[1,2,3]$ code. The thermoelastic computations were made with the Sandia version of the BNINES [4? program. COUPLEFIO is based on a formulation for creeping incompressible nonNewtonian fluid flow. The Euler equations resulting from the varz stional principle for this formulation are:

$$
\begin{gathered}
\frac{\partial \sigma_{i, j}}{\partial x_{j}}+\rho g_{i}=0 \\
\dot{\varepsilon}_{i j}=\frac{1}{2}\left(\frac{\partial u_{i}}{\partial x_{j}}+\frac{\partial u_{j}}{\partial x_{i}}\right) \\
\dot{\varepsilon}_{i j}^{\prime}=\sigma_{i j} / 2 \mu \\
\dot{\varepsilon}_{i j}=0 \\
\rho=p_{0}(1-a \Delta \mathrm{T})
\end{gathered}
$$

where $\sigma_{i j}$ and $\sigma_{i j}^{\prime}$ are the stress and stress deviator tensors; $\dot{\varepsilon}_{i j}$ is the strain-rate tensor; $u_{i}$ is the velocity vector; $g_{i}$ is the gravity vector; $\rho$ is the densicy; $\alpha$ is the volumetric expansivity; $\mu$ is the viscosity; and $\Delta T$ is the temperature rise.

Equation (1) represents a force balance on the salt. In this equation the acceleration terms have been neglected, limiting the validity 
or the analyses to flows in which the instia may be neglected in comparison to other terms in the equation. Equation (2) is a kinematic relationship between strain-rate and velocity. Equation (3) is the constitutive model used to approximate the secondary creep behavior of the salt. In the analyses presented, the viscosity is either constant or temperature dependent. Often, a Bingham viscoplastic model having a ninimum yield stress before flow beeirs is used to model the salt response. Experiments performed at Sandia [57 indicate that the :-Leld stress is negligible and that flow begins with very low stress values. In this case the Bingham model is equivalent to the model described by Equation (3). Equation (4) represents the incompressibility constraint placed on the allowed mode of deformations. Equation (5) indicates the relationship between salt density and changes in temperatures. Known velocilies or traction vectors are applied along the boundaries.

The heat transfer formulation in COUPLEFLO is based on the conductivecorvective energy equation:

$$
\frac{\partial}{\partial x_{1}}\left(k \frac{\partial T}{\partial x_{i}}\right)-\rho C_{p} u_{i} \frac{\partial T}{\partial x_{i}}+Q=o C_{p} \frac{\partial T}{\partial \tau}
$$

where $T$ is the temperature; $k$ is the conductivity; $C_{p}$ is the speciric heat; $Q$ is the heat generation rate; and $T$ is time. The heat generation rate, $Q$, decays with a prescribed half life in the transient analyses. Temperature dependent conductivity has been used in the analyses as indicated in the results. Known temperatures or heat fluxes are applied along the boundaries.

The finite element equations are formulated from a variational principle for the viscous flow equations and using Galerkin's method for 
the energy equation. Application of the Boussinesq approximation in the formulation specifles that changes in density should be considered only when computing the body forces and neglected elsewhere. The equations of motion (Equations (1)-(5)) are couplo to the energy equation (Equation (6)) through viscous dissipation, temperature dependent material properties, temperature dependent body forces, material convection, and changing geometry.

Transient analysis performed using COUPLEFLO begins with an undeformed isothermal salt merium and proceeds incrementally through time. First, the velocity jistribution is detesmined frum the momentum equetions with material properties and body forces besed on the salt at its initial temperature. The temperature distribution corresponding to the end of the first time step is then determined by solving the erergy equation using a Crank-Nicholson finite difference method in the time dorain. The salt geometry then moved ahead to its deformed configuration at the end of the first tine step though Euler integration of the velocity field. Subsequent movement of the salt is evaluated by continuing to step the solution ahead, each time using the velocities and temperatures at the end of the prior time step as Initial conditions for tho new time step.

The steady-state analyses in COUPLEFLO are performed using an iterative technique that alternates between creeping viscous flow solutions and temperature solutions. First, the temperature distribution is determined assuning no motion in the salt. Next the velocity field is determined using the temperature distribution previously obtained to define material properties and body forces. Then a new temperature distribution is obtained that includes viscous dissipation and material convectiun computed using the velocity field. The analysis continuas to alternate 
back and forth between solutions until the coupled temperature distriburion and velocity field do not change from one iteration to the next. At this point, the velocity field determined from the temperature distribution is consistent with the temperature distribution obtained using the material convection and viscous dissipation resulting from that velocity field. COUPLEFLO uses isoparemetric triengular elements with quedratic velocity approximations and linear pressure approximations. It employs a frontal solution technique with Jholesky decomposition to solve the matrix equations resulting from the finite elerent formulations.

The SANDIA-BMINES computer program is formulated for static, two- or three-dimensional stress analyses. The naterial properties package has been written especially to represent the response of geologic media. Both isotropic and anisotropic material behavior can be simulated using linear and nonlinear models. Thermoelastic stress distributions and deformations can be computed using SANDIA-BMINES. The code does not have the capabilities for heat transfer analyses, so provisions have been made for specifyin: the temperature field prior to the thermoelastic analyses.

The SAIDIA-BMINES finite element progran uses the direct stiffness method of structural analysis. Displacement degrees of freedom are defined at nodal points located at tre corners of the elements. Stress and strain values are, in general, computed at element centroids. Nodal point forces, which include external loads and internal resisting forces, are combined into a global loads vector while the element stiffnesses are consolidated into a structural or global stiffness matrix. Incremental displacements are obtained from the equilibrium equations using a form of Cholesky decomposition which involves triangularization of the global stiffness matrix, reduction of the loads vector, and back substitution of the 
reduced load vector into the triangularized stiffness matrix. Interested readers should consult Ref. 4 for detailed discussions of the element and material properties libraries, the computer processing features (i.e., multibuffering techniques which allow efficlent out-of-core processing) and sor discussions of other user oriented features such as the automatic mesh generator and the bandwidth minimizer. Discussions of the thermal stress analysis cepabilities are found in Ref. 8. 
A schematic diagram of the model used for analysis of the canist?r movement is shown in Figure 1 . Axisymmetric meshes have been uss $" r r$ both the viscous flow and thermoelastic computations. The salt region in both cases extended to a radius of $500 \mathrm{~m}$ and to horizons $750 \mathrm{~m}$ above and below the canister. The canister initially was centrally positioned in this region.

Boundary conditions for the region are also indicated on Figure 1 for both the viscous flow analyses and the thermal analyses. Kinematic constraints of zero radial velocity existed along the centerline and along the outer radial boundary while zero axial velocity was imposed on the lower horizon. The upper surface was assumed to have zero applied traction vectors. Initially, the salt and canister are motionless.

The thermal boundary conditions are also shown in Figure 1 for both the steady-state and transient analyses. In the transient analyses all boundaries were assur.ed to have zero heat flux. Throughout the transient analyses, very little temperature rise at the boundary was observed $f$.. . indicating that these boundary conditions remained valid. In $\therefore . . \quad . \quad j$-state analyses, the boundary conditions consisted of requiring tr:. ail outside boundaries remained at the initial salt temperature. The initial temperature was $313 \mathrm{~K}$ and is constant throughout the region.

The heat source was modeled with several point sources within the canister volume. These fuit; sources decayed in the trensient analyses with a 30 year half life. In the steary-state analyses the heat source was assumed to have a constant value equal to the maximum (initial) source strength for all times. 
The finite element mesh used for both the heat transfer ard creeping viscous flow computetions is shown in Figure 2. The central portion of the mesh has been enlarged to show detalls of the mesh in the vicinity of the canfater. The canister is represented by the two elements along the region axis of symmetry and centered at $750 \mathrm{~m}$ depth. The total mesh consigts of 208 triangular elements. Each element has six nodal points glving a quadratic approximation for velocity and a linear pressure approximation. The radius (maximum) of the canister is $0.625 \mathrm{~m}$ at its center and has a double cone shape. The overall lengtr, is approximately $3 \mathrm{~m}$. A second mesh was constructed for viscous flow computations in which finer discretization was imposed around the canister. This allowed for modeling a smaller radius (.278 m maximum at the center) canister. This mesh has 272 triangular elements, 603 velocity nodal points, and 437 pressure nodal points. Details of the zone near the canister are shown in Figure 3.

In the thermolastic analyses the left hand (inner) boundary simulates the centerline of this axisymmetric model; only vertical motion was a?iowed along this axis. No radial motion was allowed along the outer boundary of the model but the nodal points along this surface were free to move vertically. The bottom boundary was assumed to be rigid, i.e., nither horizontal nor vertical motion was allowed. The top of the model had no displacement or traction boundary conditions imposed. The transient temperatue fields computed using the COUPLEFL program were used as input to the thermoelastic analysis.

The finite element mesh used in the thermolastic model consists of 680 quadrilateral elements. Each elemerit has four nodal points (one at each corner of the element) and two displacement degrees of freedom, $u$ and 
$\checkmark$, at each node. Wilinear displacement functions are used to represent the varietion of the displacement components within en element. There Are 735 nodal points in the mesh. After the boundary conditions have been applied, there are 1369 degrees of rreedom remalning in the mesh. A prition of the mesh in the region nearest the canister is shown in Fifure 4.

The material property values used in the analyses are the best estimates currently available. In the courge of the analyses, several values of viscosity and conductivity were considered within the ranges of measured values. The property values are summarized in Table 1 with the sources of information. 


\section{RESULIS OF THE ANALISES}

Before analyzing canister movement associated with broyant rising of the sa..t env, roment, a test case involving the sinking of a norhest producing cantster in an 1sothermal salt medium was examined. The predicted downward velocity was autte $\operatorname{small}, 29 \mathrm{pm} / \mathrm{sec}(24 \mathrm{~m} / 1000 \mathrm{yr})$, for salt with a viscosity $(\mu)$ equal to $0.5 \times 10^{14} \mathrm{~Pa}-\mathrm{sec}$. Th1s velocity compares well wth the velocity of $23 \mathrm{pm} / \mathrm{sec}(19.2 \mathrm{~m} / 1000 \mathrm{yr})$ computed using a simple Stokes' sphere model in which the drag force was equivalent to that of a sphere with the same diameter as the canister approximation in throfinite element solution.

Coupled transient analyses of the canister and salt motion were performed for models with constant and with variable salt viscostty. The salt conductivity in these analyses corresponds to the temperature dependent relationship listed in Table 2. Anelysis using constant viscosity $\left(\mu=0.5 \times 10^{15} \mathrm{~Pa}-\mathrm{sec}\right)$ has been carried out to a time of 10 years. Initially, the canister began to sink since the surrounding salt was isothermal and the canister density $\left(4100 \mathrm{~kg} / \mathrm{m}^{3}\right)$ was greater than the salt. Heat from the westes raised the salt tempereture near the canister, provlding the buoyent force necessary to start upward flow of the salt. The total canlster velocity as a result of the upward salt velocity diminished. Eventually, the strength of the convective cell of the salt was sufficient to give the ganister itself an upward velocity. The maximum cantster velocity obteined during the 10 year period of analysis was $1.5 \mathrm{pm} / \mathrm{sec}$. The total displacement during this time was .0001 $\mathrm{m}$.

The transient analysis of the salt canister system using a model with temperaturi dependent salt viscosity (Table 1 ) has been performed using 
COUPIEF!' for times out to approximately 150 years. Again the canister started from rest in an isothermal salt, medium and began to sink. Using the temperature dependent viscosity model, however, the downward velocity of the canister initially increased as salt in the viscosity of the canister was heated. This was a resilt of the reduced viscosity of salt near the canister allowing the canister velocity relative to the salt to increase faster than the convective cell formed in the salt. Eventually, the convecitive cell gained strength and reduced the total canister velocity. After approximately 35 years the canister velocity became positive and subsequently obtained a peak upwara velocity of $0.1 \mathrm{pm} / \mathrm{sec}$. After epproximetely 125 years, the convective cell velocity had diminished and the canister began to move downward again. The total displacement during the 150 years of analysis was $-.0003 \mathrm{~m}$. The velocity history for the 150 year period is shown in Figure 5. The thermal history for points within the canister, at $10 \mathrm{~m}$ away from the canister, and $30 \mathrm{~m}$ away from the canister heve been plotted in Figure 6 . The convective circulation associated with the flow of salt can be readily seen from the velocity field depicted in Figure 7. Arrows in this figure indicate the direction of flow and are not proportional in length to the velocity magnitude. Steady-state analyses were performed to provide an upper bound on the magnitude of canister velocities. In these analyses the canister heat output was assumed to be constant and to equal the maximum (initial) power of the wastes. A variety of cases have been examined to study the effects of different canister densities, variable and constant viscosity, variable and constent thermal conductivity, and canister mesh sizes. The results of these analyses are presented in Table 2. It is important to note that the velocities predicted in the steady-state analyses cannot be 
used to predict movement beyond periods in which significant heating occurs. Rather, predicted velocities can only be interpreted as maximum upper bounds of velocity for some time curing heating (less then 3000 years from time of emplacement).

The greatest upward velocity $(26.5 \mathrm{pm} / \mathrm{sec})$ was predicted for the case of constant viscosity and conductivity. In this case the canister density was $4100 \mathrm{~kg} / \mathrm{m}_{4}$. The canister velocity decreases when temperature dependent conductivity was included in the model. This was due to steeper thermal gradients near the canister that produced a smaller zone of low density salt. Thus, the driving force of the convective cell was less. By considering the temperature dependent viscosity of the salt, the canister's upward velocity was observed to diminish further. This was because the reduced viscosity in the vicinity of the canister (hot zone) increesed the canister's velocity relative to the salt more then it increased the velocity of the convective cell within the salt medium. The effect of varying the canister's density is shown in Figure 8 . The density of $5800 \mathrm{~kg} / \mathrm{m}$ can be seen to produce almost zero velocity. In this case the canister was sinking in the salt with nearly the same velocity that the salt was rising. As the carister density decreased, the velocity of the canister in the salt decreased and the overall motion of the canister was upward.

The effect of meshing was also examined. The previous results were obtained using a relatively large canister radius $(r=.615$ on at the widest point). Specifying a smaller radius $(r=.276 \mathrm{~m})$ resulted in larger drag forces relative to the buoyant forces. Thus, the upward velocity of the canister increased. For the constant salt viscosity $\left(\mu=.5 \times 10^{14} \mathrm{~Pa}-\mathrm{sec}\right)$ and constant salt themal conductivity the canister 
velocity was $283 \mathrm{pm} / \mathrm{sec}$; whereas, for variable conductivity and viscosity (Table 1) the canlster velocity was $2.5 \mathrm{pm} / \mathrm{s}$. In both cases the caniater density was $i_{1} 100 \mathrm{~kg} / \mathrm{m}^{3}$. The convective cell salt velocities end temperature distributions were the same for both mesh configurations.

The displecement of the surface at the repository centerline, os predicted by the thermoelastic model, is shown in Fig. 9. The maximum gmount of surface motion which can result from the emplacement of the canister occurred at this point. The motion wes once again quite small, i.e., less then .15 mm after 30 years. The canister rise due to expansion of the selt was at least an order of magnitude less than the surface matior.

It should be roted that in calculations (see Ref. 9) simiating the response of a large repository the surface motion increases with time for approximately tha first 100 years and then remains relatively constant during the noxt several hundred years. It would, therefore, be unrealistic to Extragrate the results shown in Fig. 9 to long periods of timne.

The results were also examined in terms of the validity of the ossumption that inertio terms could be neglected fron Equation (1). Equation (1), including inertia terms, can be written as follows:

$$
\sigma_{i j, j}-\rho\left(\dot{u}_{i}-g_{i}\right)=0
$$

In the analyses conducted, acceleration of the velocity field, $\dot{u}_{i}$, was small in comparison to the gravit Sional constant, $g_{i}$. Thus, the quantity ( $\dot{u}-g_{i}$ ) is closely approxinated by $\left(-g_{i}\right)$. This indicates that neglecting inertia terms in valia. 


\section{CONC LUS IONS}

The analyses performed indicate that very little canister movement will result during the heat froducing life of the waste canisters. The transient analyses show that initially the canister wiil sink. Due to the formation of a conventive cell in the salt from heating by the wastes, the canister will rise. Eventually, as the convective cell diminishes the canister begins to sink again. Predicted displacements are less than a canister length during this process. The steady-state analyses provide upper bounds on the magnttudes of upward velocity possible during heating. In all ases, the velocities are sufficiently smll to indicate very little movement will occur while the canister is capable of producing heat. The thermoelast:c analyses predict little surface upheaval and indicate that the free expansion assumption used in the viscous flow analysis is reasonable.

The onalyses performed apply only to a single cantster in a large salt medium. The combined effect of many canisters cannot be inferred -from superposition of the single canister results. Separate analyses are being performed to address the multiple canister probzem. 
REFERENCES

1. Sato, A, and E. G. Thompion, "Finite Eloment Mclels for Creeping Convection," Journal of Computational Fhysics, 22, 1976.

2. Thompson, E. G., "Average and Complete Incompressibility in the Finite Element Method," International journal for Numerical Methods in Engiseering, Vol. 9, 925-932, 1975.

3. Dawson, P. R., "Flnite Element Thermcnechanical Models for Metal Forming," Ph.D. Thesis, Colorado State University, Fort Colins, Co, Fall, 1976.

4. Isenberg, Jeremy, "Analytical Modeling of Rock-Structure Interaction," 3 Volumes, Final Technical keport of ARPA Contract H0220035, Agbabian, Associates, El Segundo, CA, April 1973.

5. Personal communtcation with w. Wawersik, Division 5163, Sendia Laboratories, Albuquerque, NM.

6. Baumeister, Theodore, (Editor), Mark's Standard Handbook for Mechanical Engineers, Seventh Edition, McGraw-Hill Book Compeny, New York, 1967.

7. Thermomechanical Properties of Matter, Purdue University, Thermophysical Properties Research Center, 1970.

8. Tillerson, J.R. and M. M. Madsen, "Thermoelastic Capabilities of the SANDIA-BMINES Program," SAND-77-0379, Sandia Iaboratories, Albuquerque, iM.

9. Dawson, P. R. and J. R. Tillerson, "Salt Motion Following Nuclear Waste Disposal," Proceedings of the International Conference on Evaluation and Prediction of Subsidence, Pensacola, FL, Jan. 15-20, 1977. 
Salt:

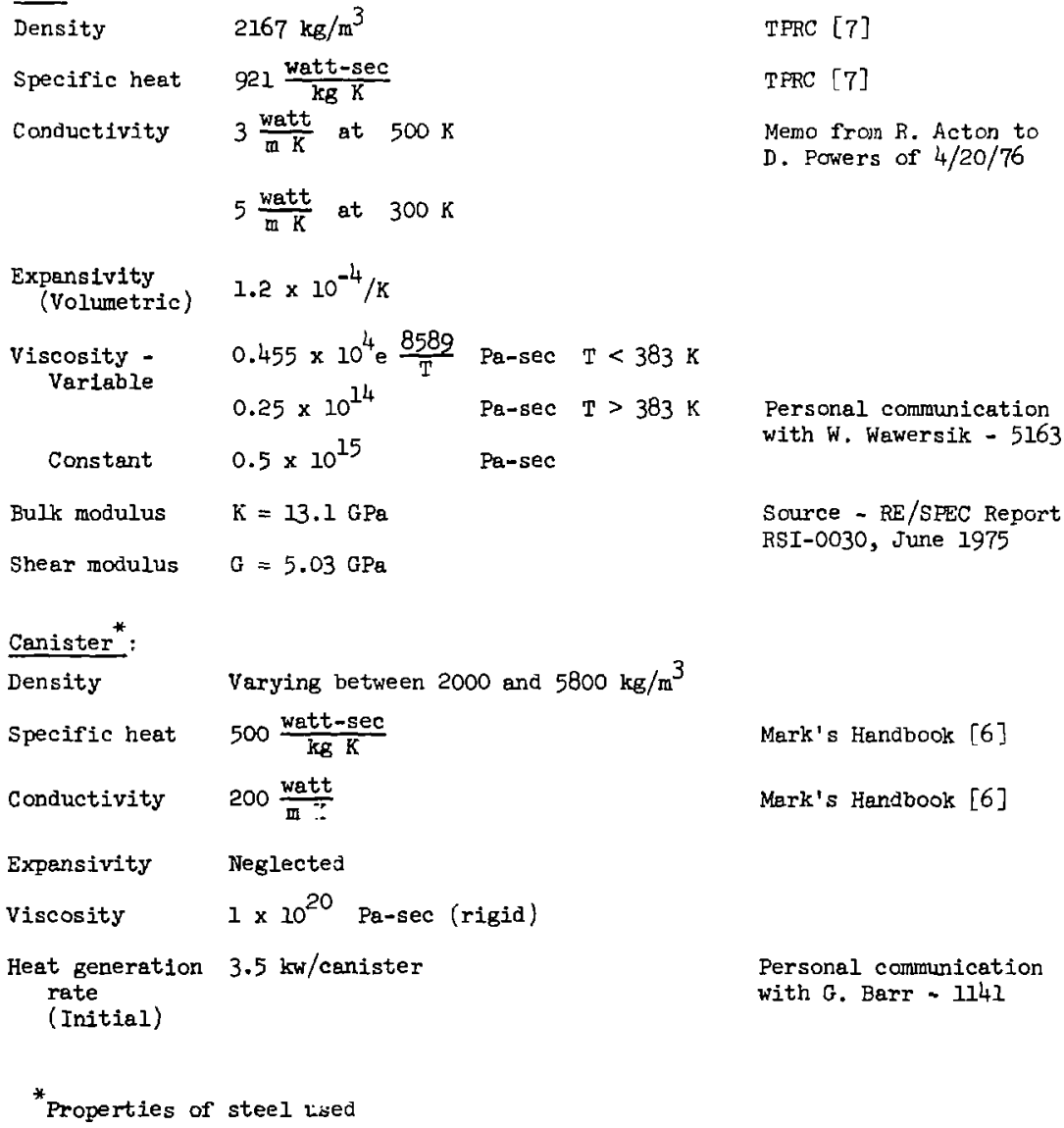


TABLE 2

Steeay-State Canloter Movement ${ }^{\dagger}$

\begin{tabular}{|c|c|c|c|c|c|c|}
\hline Case & Conductjuity & viscosity & $\begin{array}{l}\text { Canister } \\
\text { Density }\end{array}$ & $\begin{array}{c}\text { Canlater } \\
\text { Centerline } \\
\text { Hadius } \\
\end{array}$ & $\begin{array}{c}\text { Velocity } \\
\left(\times 10^{10} \mathrm{~m} / \mathrm{sec}\right) \\
\end{array}$ & $\begin{array}{l}\text { Traveled in the } \\
\text { F1rit } 3000 \text { Years } \\
\text { After Emplacement }\end{array}$ \\
\hline$\Lambda$ & Constant & Constant & 4100 & .625 & .265 & $2.51 \mathrm{~m}$ \\
\hline B & Variable & Constent & 4100 & .625 & .215 & 2.03 \\
\hline $\mathrm{C}$ & $v$ & $v$ & 2000 & .625 & .037 & 0.35 \\
\hline D & $v$ & $v$ & 3000 & .625 & .027 & 0.26 \\
\hline$E$ & $v$ & $v$ & 4100 & .625 & .0165 & 0.16 \\
\hline $\mathbf{F}$ & $v$ & $v$ & 5800 & .625 & -.0001 & -.001 \\
\hline G & $v$ & $v$ & 4100 & .278 & .025 & .25 \\
\hline H & c & $c^{*}$ & 4100 & .278 & 2.83 & 28.3 \\
\hline I & $\mathrm{v}$ & $c^{*}$ & $\$ 100$ & .625 & 2.09 & 20.9 \\
\hline
\end{tabular}

$$
\begin{aligned}
& \text { Conductivity Constant } \quad 4.0 \frac{\text { wetc }}{m \mathrm{~K}} \\
& \text { Variable } \quad 10.76 \mathrm{e}^{-2.554 \times 10^{-3} \mathrm{~T}} \frac{\text { watt }}{\text { m K }} \\
& \text { Viscosity Constant } \quad \mu=0.5 \times 10^{15} \text { Pemsec } \\
& \text { Variable } \quad \mu=.455 \times 10^{4} \mathrm{e}^{8589 / T} \text { Pa-sec } \\
& \text { for } \mathrm{T} \geq 383 \mathrm{~K} \\
& \mu=0.25 \times 10^{14} \mathrm{~Pa}-\mathrm{sec} \\
& \mathbf{T}<383 K
\end{aligned}
$$

*Viscosity $\mu=0.5 \times 10^{14}$ Pa-sec (extremely low)

'steady-state analyses provide only an upper bound to the maximum canister velocity. The results cannot be used to determine overall movement over lang periods of time. Rather, velocities can only be used to place an upper boumd on movement while movement is occurring (times less then 3000 years). During the first 3000 years following emplacement, the use of a constant source equal to the initial (maximum) power provides 70 times too much eneray to the system. 


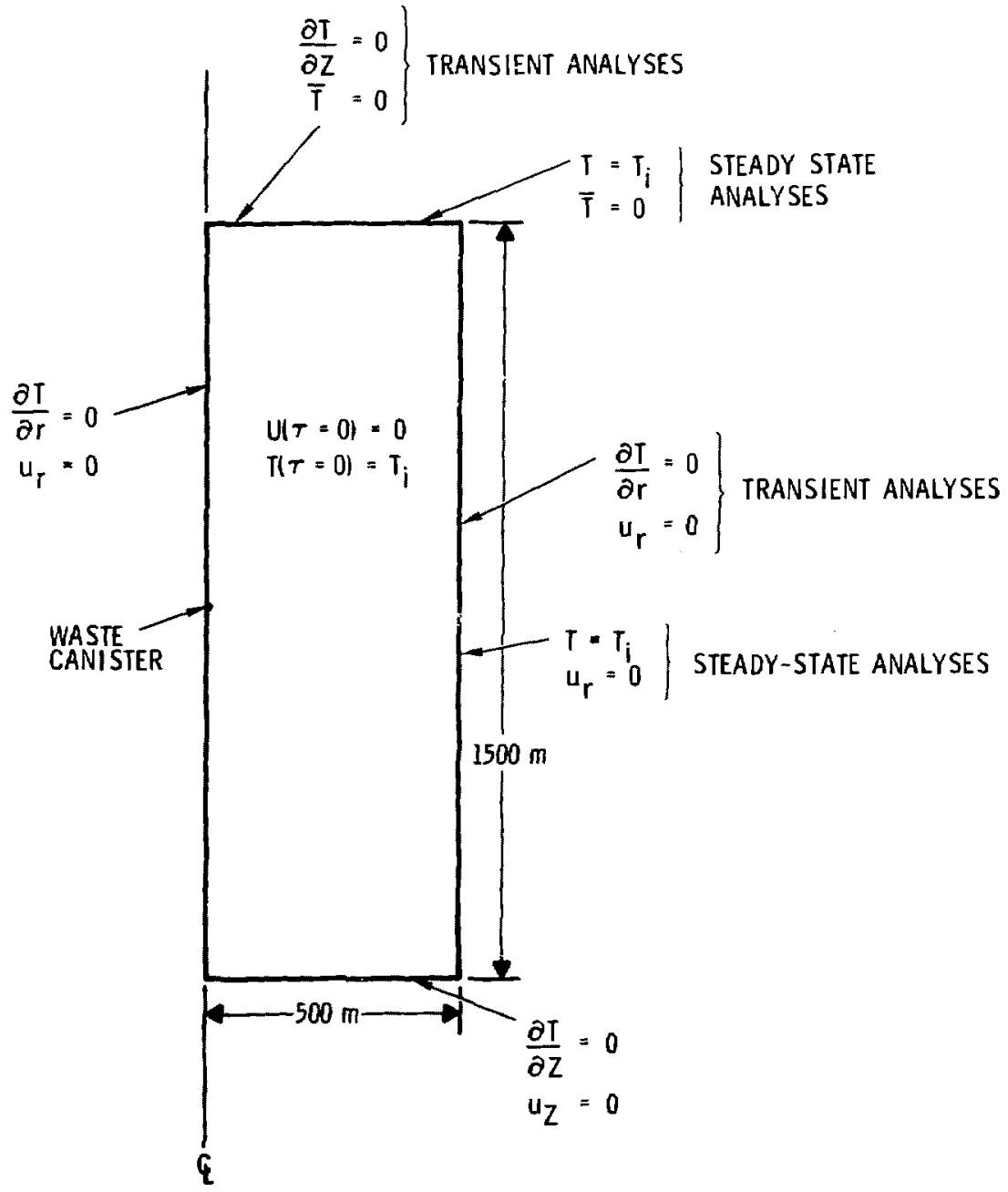

Figure 1. Cantster Movement Axisymetric Model 


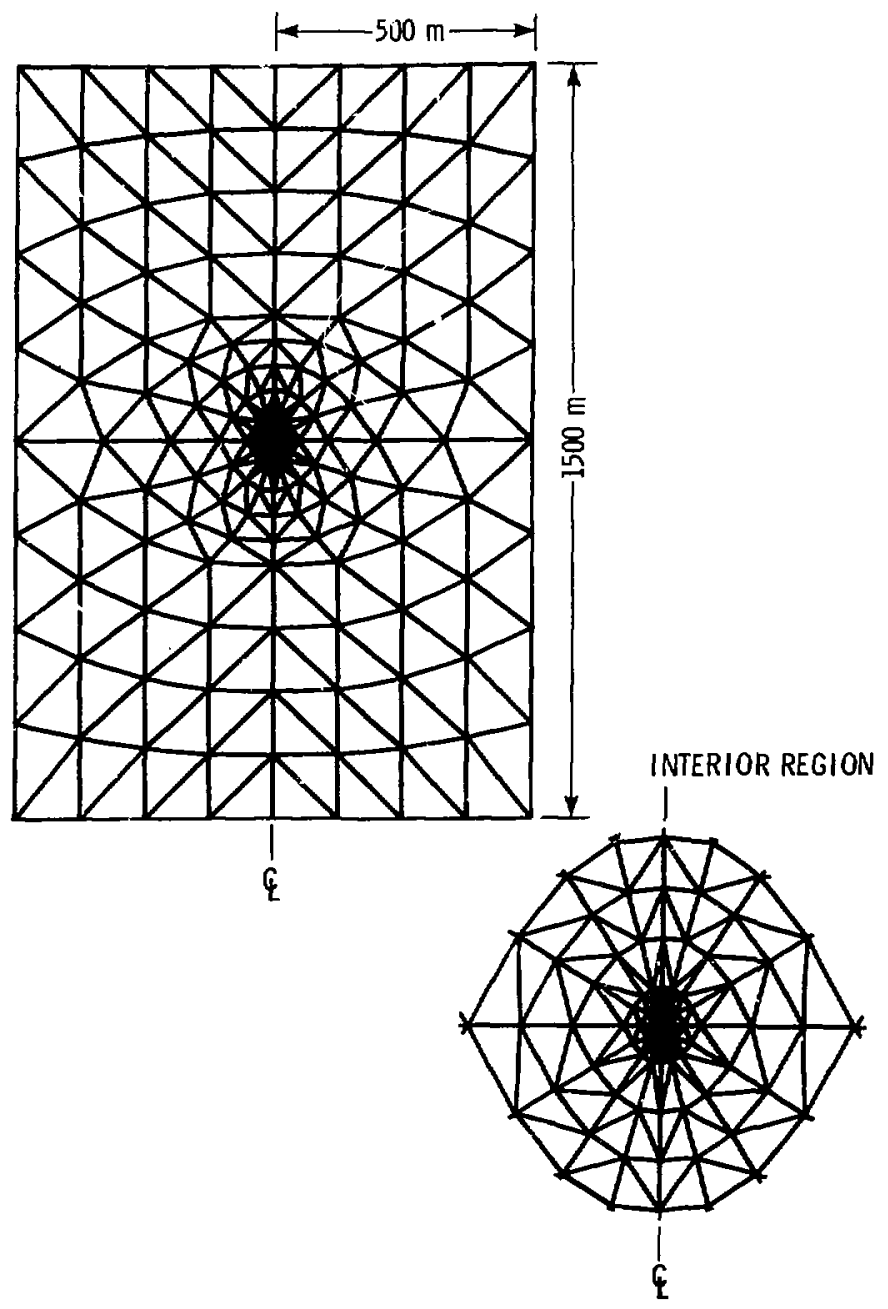

Figure 2. V1scoplastic Flow and Heat Transfer Coarse Mesh 


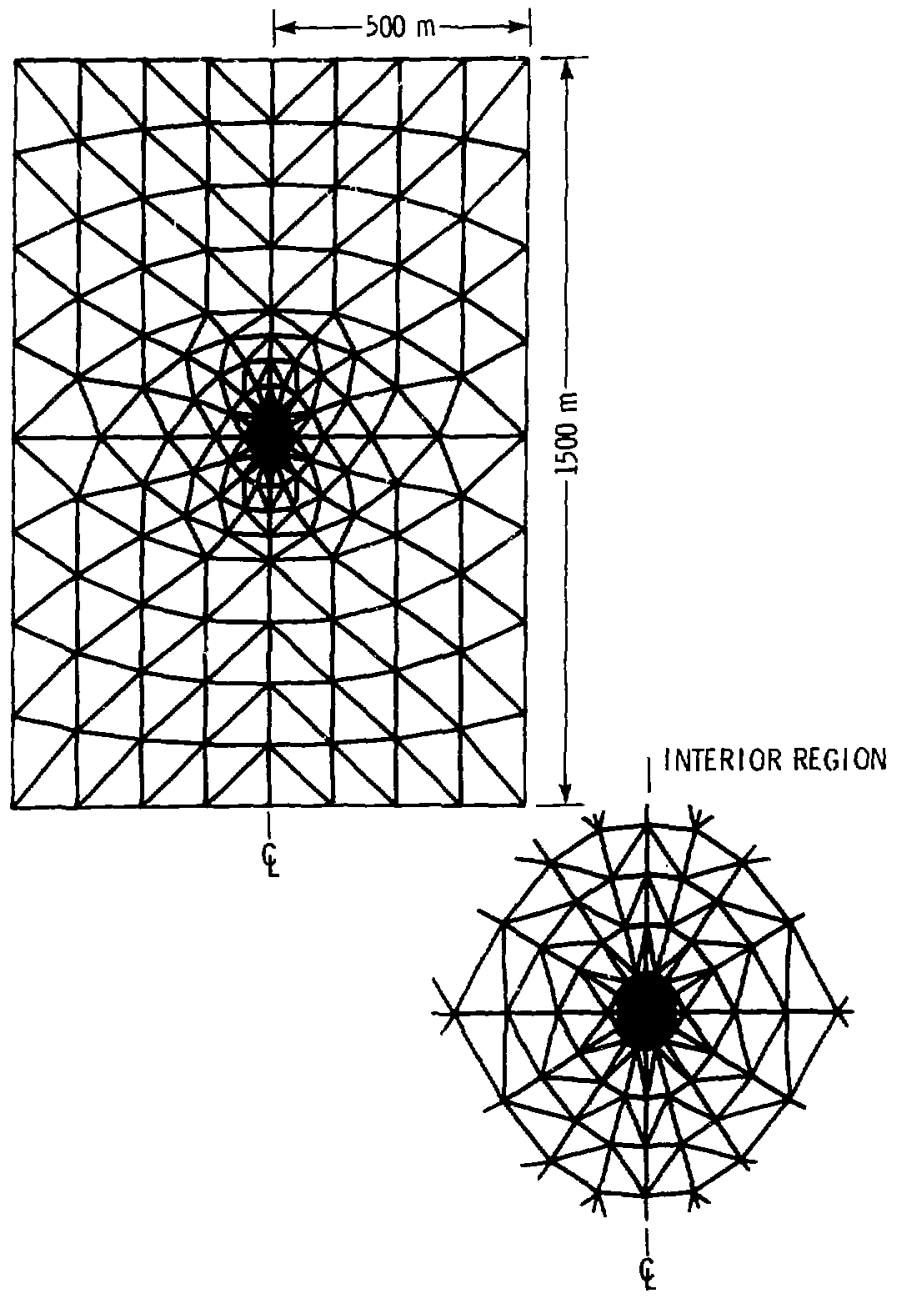

Figure 3. Viscoplestic Flow and Heat Transfer Fine Mesh 


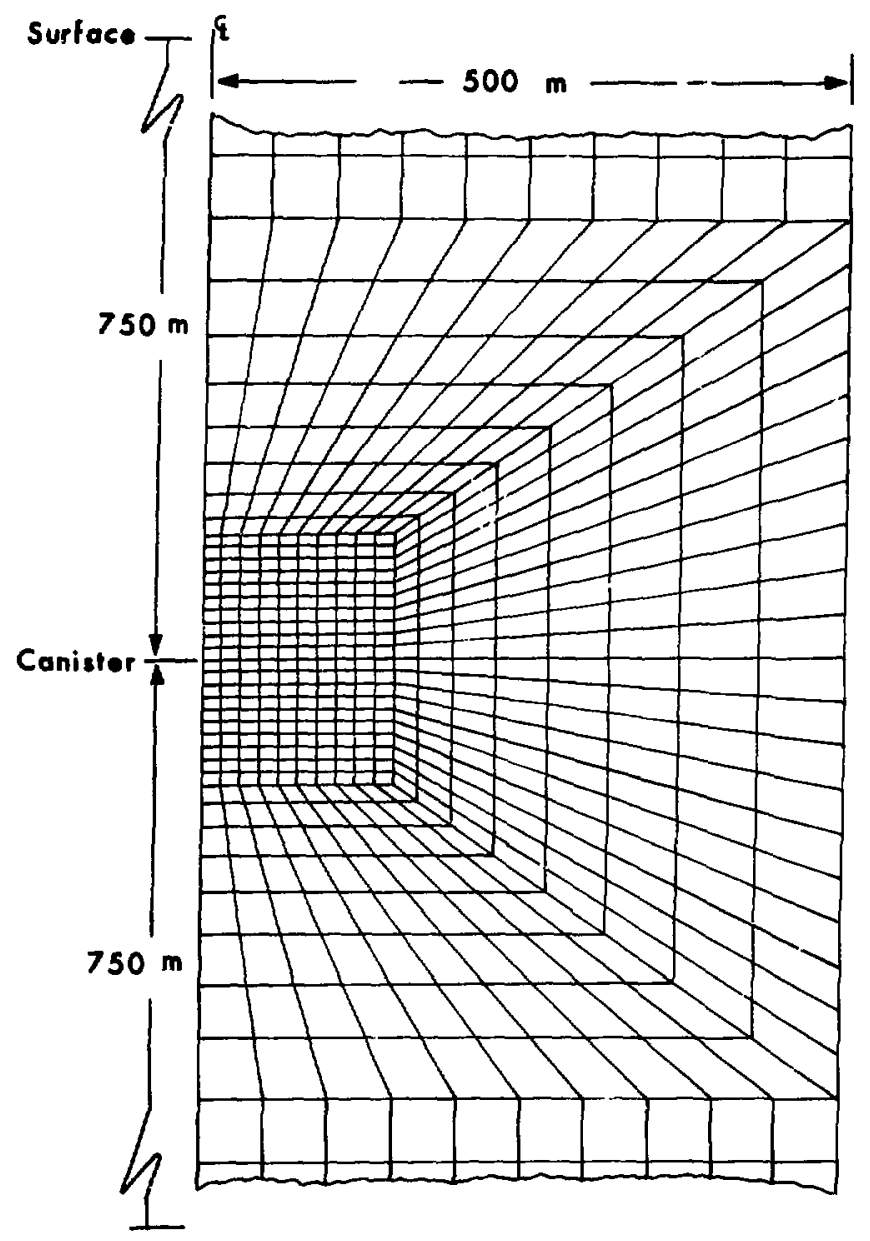

Figure 4. Thermoelastic Finite Element Mesh 


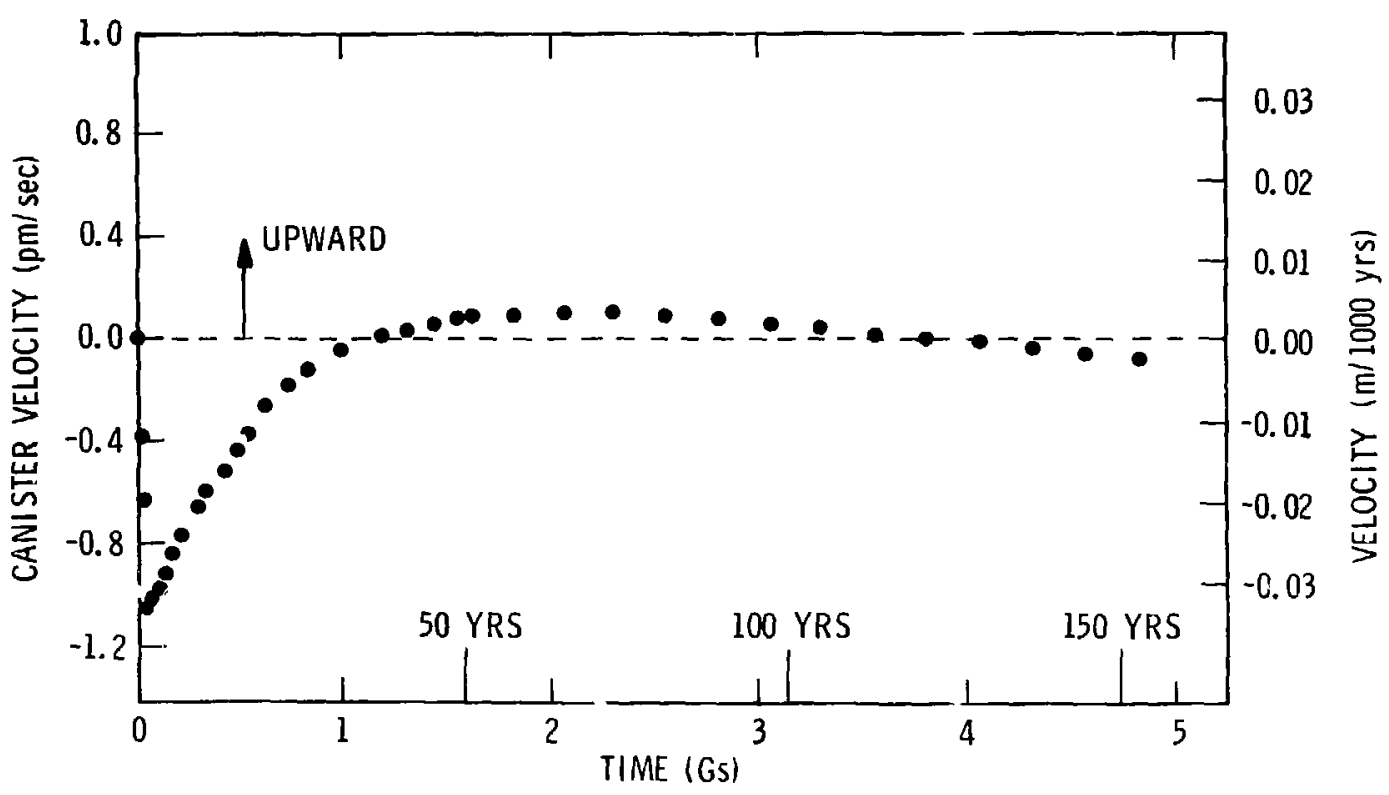

Figure 5. Canister Velocity History 
œ

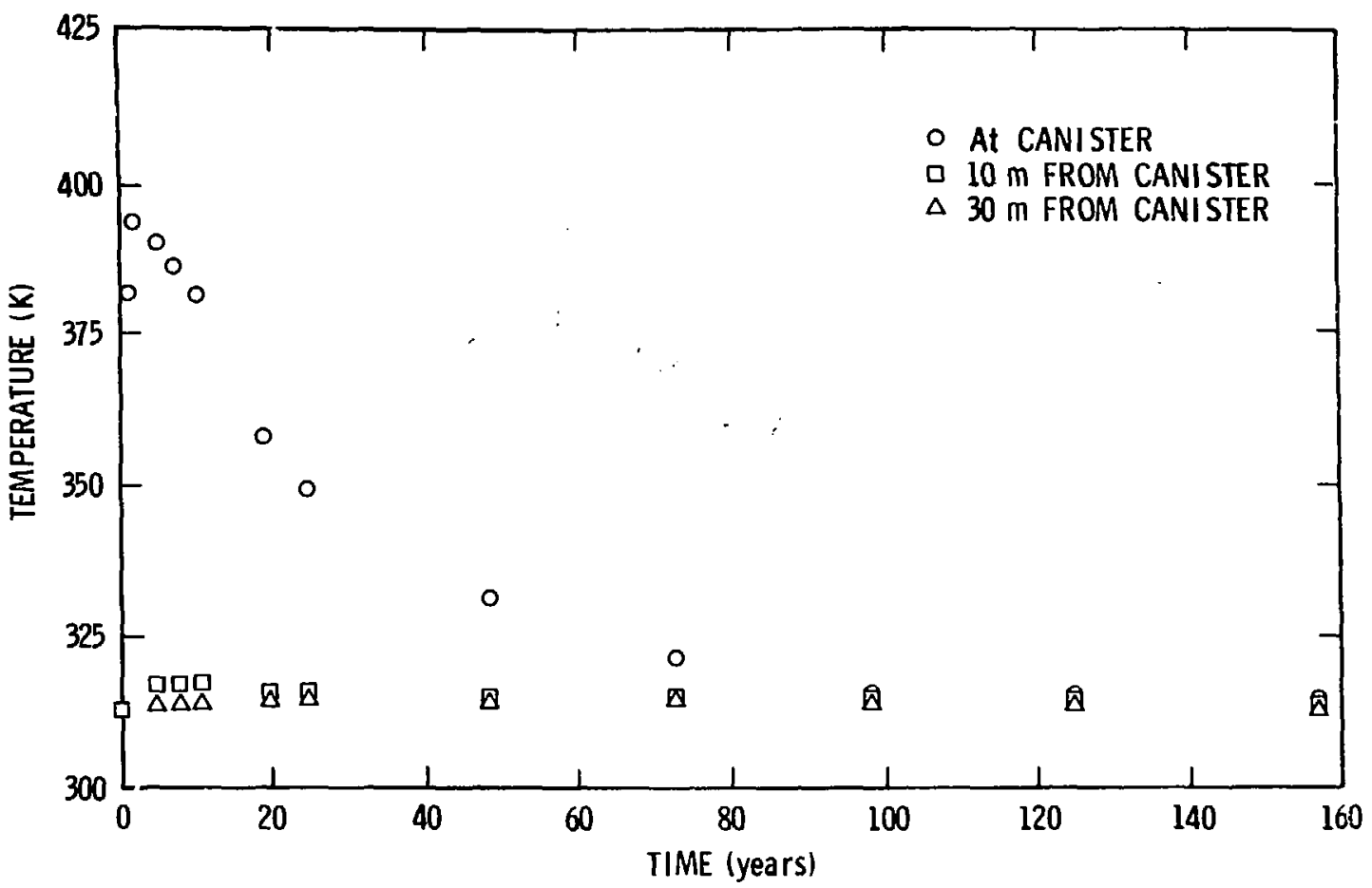

Figure 6. Salt Thermal History 


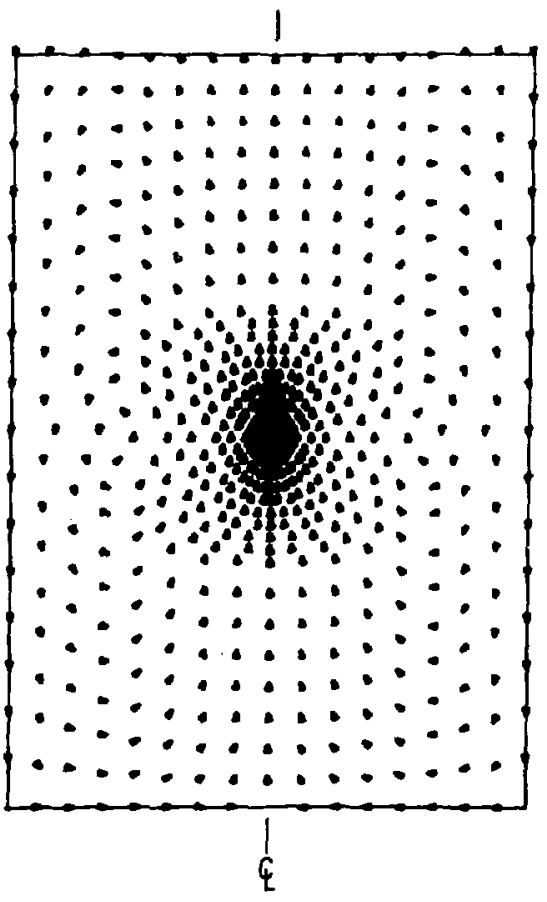

INTERIOR REGION

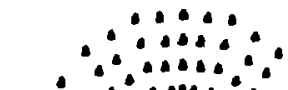

$$
\begin{aligned}
& \because \because+4000 \\
& \because \because \because p \text { bै: }
\end{aligned}
$$

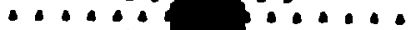

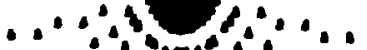

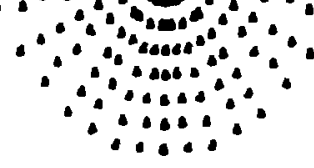

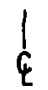

Figure 7, Salt Velocity Field 


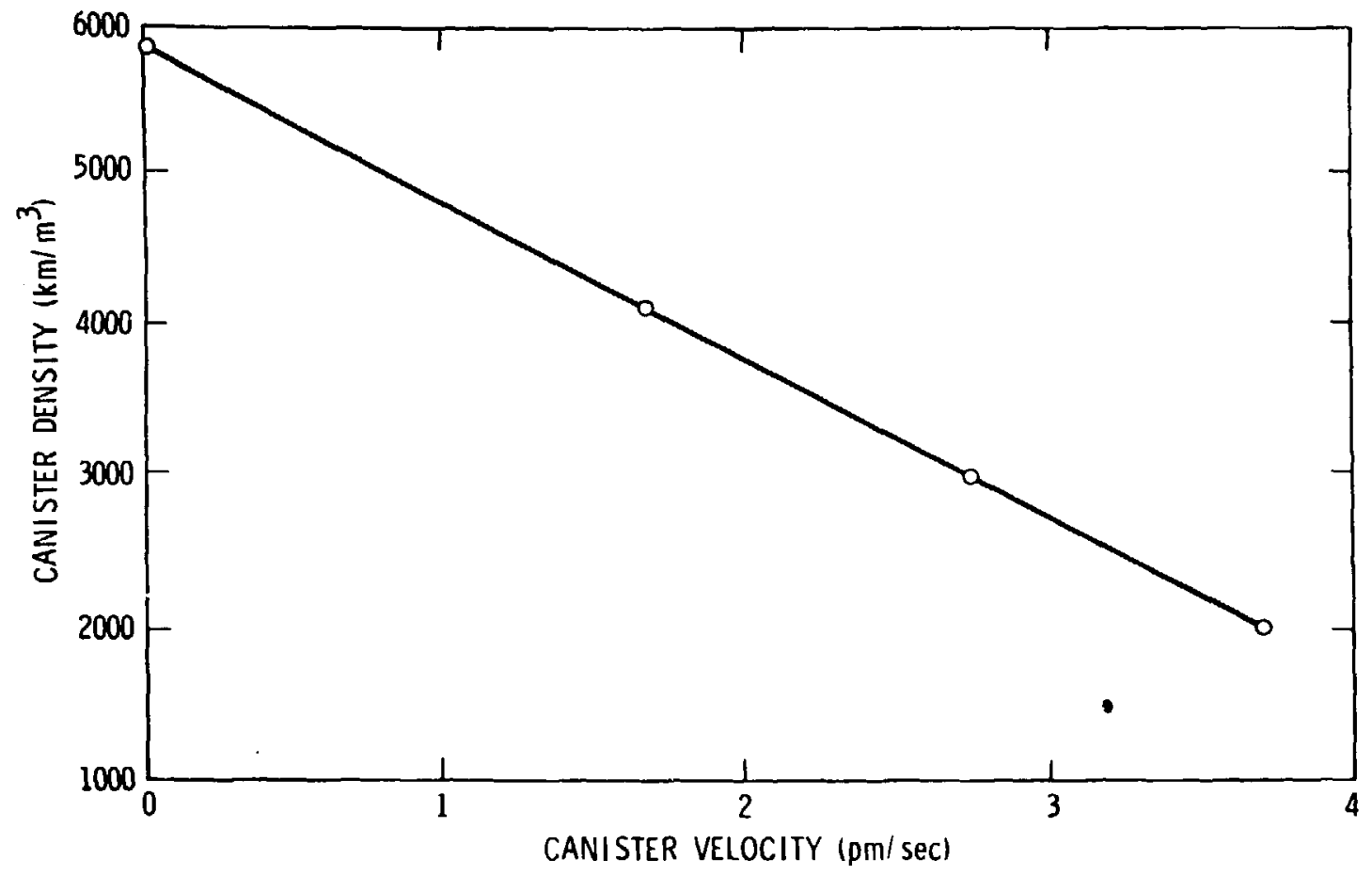

Figure 8. Canister Density Effect on Canister Velocity 


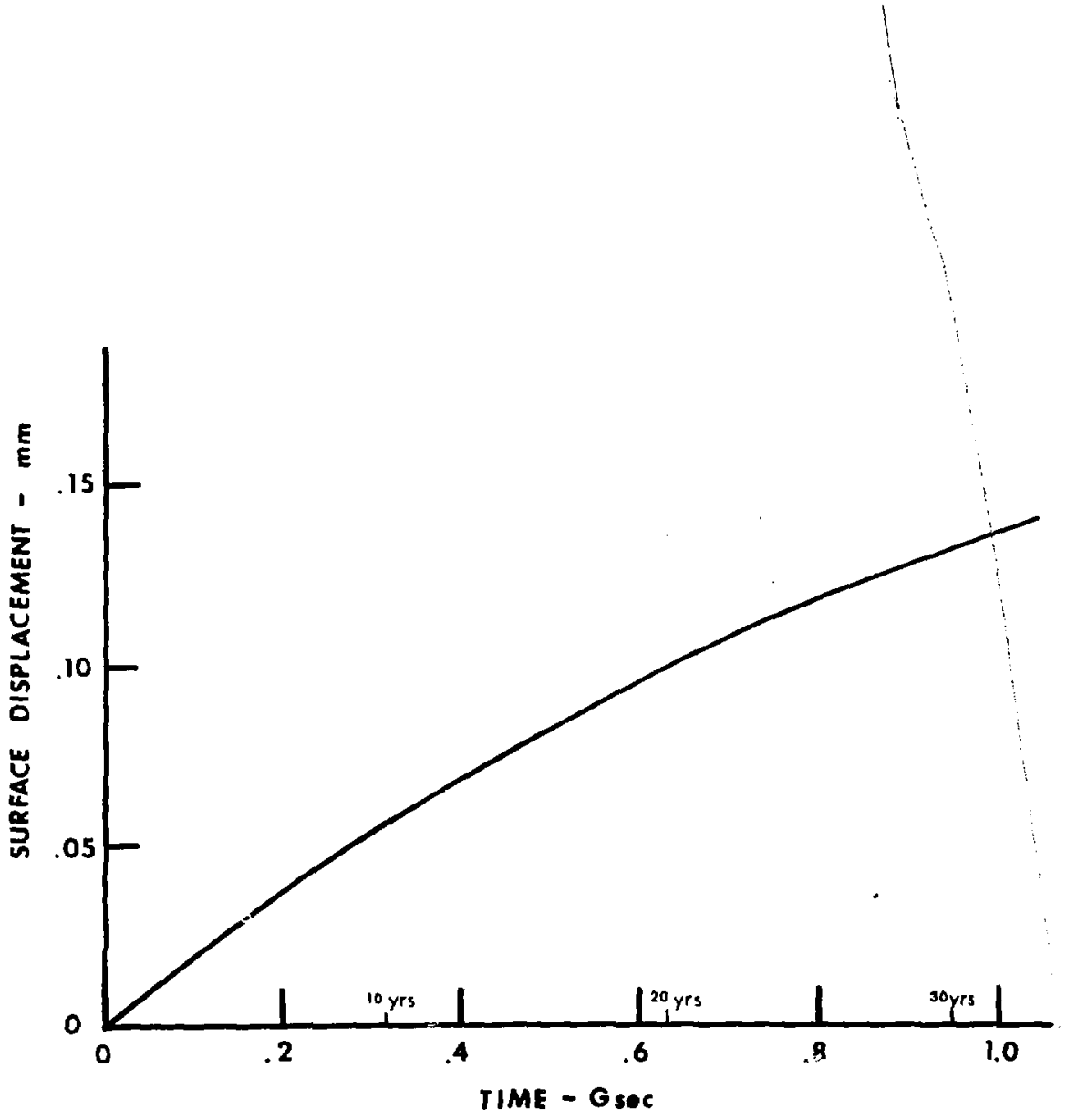

Figure 9. Surface Ris= Resulting from Thermolastic Behavior 